\title{
Compraventa con reserva de propiedad
}

Manuel De la Puente y Lavalle

El artículo $1583^{\circ}$ del Código Civil dispone lo siguiente:

Artículo $1583^{\circ}$.- En la compraventa puede pactarse que el vendedor se reserva la propiedad del bien hasta que se haya pagado todo el precio o una parte determinada de él, aunque el bien haya sido entregado al comprador, quien asume el riesgo de su pérdida o deterioro desde el momento de la entrega.

El comprador adquiere automáticamente el derecho a la propiedad del bien con el pago del importe del precio convenido.

\section{Campo de aplicación}

No existe uniformidad en las codificaciones en cuanto a los bienes respecto de los cuales es posible pactar la compraventa con reserva de propiedad.

El Código Civil italiano, por ejemplo, ubica este contrato en la sección que versa sobre la venta de cosas muebles.

Sin embargo, la mayoría de la doctrina italiana ${ }^{1}$ se pronuncia en el sentido de que el pacto de reserva de dominio es válido respecto también de bienes inmuebles por cuanto, a falta de una norma prohibitiva

1 Guido Capozzi, Dei singoli contratti, Giuffré Editore, Milano, 1988, p. 126; Massimo Bianca C. La vendita e la permuta, Unione Tipografico-Editrice Torinese, Torino, 1972, p. 534. 
-que, por otro lado, no tendría justificación-, prevalece el dominio de la autonomía de la voluntad.

El BGB dispone en su numeral 925 que es ineficaz la transmisión de propiedad de una finca que se realice bajo una condición o una determinación de tiempo, de lo que se colige que no es posible el convenio por el cual el vendedor se reserva la propiedad de una finca hasta el pago del precio, ni bajo condición suspensiva, ni bajo condición resolutoria.

El Código Civil argentino viene a adoptar una solución similar a la del Código Civil italiano, pues su artículo $1374^{\circ}$ "prohibe el pacto comisorio en la venta de cosas muebles" y el artículo $1376^{\circ}$ expresa que "la venta con pacto comisorio equivale a la que se hiciera con la cláusula de reservar el dominio de la cosa hasta el pago del precio".

Empero, la doctrina argentina prevaleciente ${ }^{2}$, siguiendo a Saravia, opina que es perfectamente posible -tomando en consideración que la transmisión de la propiedad no se opera solo consensu, sino que se requiere la entrega de los bienes muebles hasta que el comprador pague el precio convenido.

Entre nosotros León Barandiarán ${ }^{3}$ y Arias Schreiber ${ }^{4}$ afirman, el primero respecto al Código Civil de 1936 y el segundo respecto al Código Civil de 1984, que la reservación de propiedad puede funcionar ya el bien sea mueble o inmueble, pues dichos códigos no hacen diferenciación alguna.

\section{Función del pacto de reserva}

Es posible que la primera manifestación legal de la compraventa con pacto de reserva de propiedad no haya sido el Derecho Romano sino que, según afirman Leonhardt y Cohen ${ }^{5}$, fuera una convención germana de garantía llamada Chursächsische Prozessordnung, cuya función fue

2 Luis María, Rezzonico, Estudio de los contratos, Ediciones Depalma, Buenos Aires, 1967, Tomo I, p. 407, Ernesto C. Wayar, Compraventa y permuta, Editorial Astrea, Buenos Aires, 1984 , p. 510 .

3 José León Barandiarán, Contratos en el Derecho Civil peruano, Comisión Editorial de la Facultad de Derecho de la UNMSM, Lima, 1965, Tomo I, p. 74.

4 Max Arias-Schreiber Pezet, Exégesis del Código Civil peruano de 1984, San Jerónimo, Ediciones, Lima, 1988, Tomo II, p. 116.

5 Cita de Luis María Rezzónico, op. cit., Tomo I, p. 507 
evolucionando con el correr de los años hasta los finales del siglo XIX, donde encontró cómoda cabida en la doctrina mundial.

Sin embargo, la expansión del mercado de bienes muebles en el siglo XX, que determinó el pasaje de un capitalismo individualista a un capitalismo asociacionista, dio lugar a un fenómeno nuevo, no previsto hasta entonces. Se trata de un cambio de mentalidad del público, inducido por una publicidad desmedida, que se ha visto envuelto en una desenfrenada carrera por adquirir bienes, especialmente muebles. Alonso $^{6}$, quien en la cita a pie de página ${ }^{7}$ hace una vívida descripción de este fenómeno, considera que la reserva de propiedad cumple en nuestros días una función intimidante.

Messineo ${ }^{8}$, por su parte, opina que la venta con reserva de propiedad cumple las siguientes funciones económicas:

a) Facilita la venta a favor de aquellos que (de ordinario, por escasez de medios) no están en situación de pagar "al contado". Tal tipo de

6 Mariano Alonso Pérez, El riesgo en el contrato de compraventa, Editorial Montecorvo S.A., Madrid, 1972, p.370.

7 El comprador, víctima de la sociedad tecnológica y de su secuela el afán de consumo por la atracción constante de la propaganda alienadora, no frena fácilmente su capacidad adquisitiva. Pretende superar todos los récords y adquirir los últimos modelos de los infinitos bienes que brinda nuestra sociedad aburguesada y prometeica (automóviles, neveras, televisores, máquinas de escribir, etc.). No importa si se dispone de dinero suficiente; pero sí importa, y mucho, responder al impacto de la propaganda que se infiltra hasta en lo más recóndito del subconsciente; adquirir sin medida para situarse a la cabeza de tantas víctimas alienadas por el consumo como los viejos navegantes por las sirenas mitológicas. También los vendedores, presionados por la gran variedad de artículos que pueden ofrecer a los compradores, sólo desean lanzar sus artículos, desprenderse de ellos: vender a quien sea y como sea. Unos y otros se sienten inmersos en un mundo que los tiraniza por igual.

Obsérvese que el riesgo inherente al hecho de que el vendedor se reserve la propiedad es más aparente que real. Es tal la necesidad de vender, se produce tanto en nuestra sociedad tecnificada y empresarial, que sin duda a los compradores se le ofrecen posibilidades de todo tipo: vendedores que desean retener el dominio de los productos y vendedores para los que lo único importante es vender, desprenderse de sus artículos como sea.

Se me objetará que el derecho de prenda ya intimida. Y es cierto, pero menos. Al comprador, seducido por la demiurgia de la sociedad de consumo, la verdad que ni la reserva de dominio, ni la garantía real le intimidan eficazmente. Mas es claro que en su inconsciente opera con más energía la idea de que la propiedad es un derecho fundamental, el "tabú" del dominio como plena in re potestas. Considera peor situación usar una cosa sin ser dueño y desea adquirirla con más afán que si ya tiene el dominio, pero se ve afectado por una posible ejecución pignoraticia.

8 Franceso Messineo, Manual de Derecho civil y comercial, Ediciones Jurídicas Europa-América, Buenos Aires, 1971, Tomo V, p. 83. 
venta permite atribuir la posesión inmediata de la cosa, también el inmediato goce de ella.

b) Mediante el goce, la cosa vendida, si es cosa fructífera, produce rédito inmediato al comprador y lo pone en situación de pagar las cuotas del precio, de la manera que, en cierto modo, la cosa se paga, aunque sea lentamente, por sí misma, o sea, con el producto de su utilización (piénsese, de modo particular, en el caso de las máquinas).

c) La venta con reserva de propiedad permite el comprador obtener uno de los atributos normales de la propiedad (el goce), aun si que haya pagado (o pagado enteramente) el precio de la cosa, mientras que, con la reserva de propiedad, que funciona como condición suspensiva, queda en el vendedor el poder de disponer, o sea, el otro atributo de la propiedad, aun cuando de tal poder no pueda valerse sino cuando el comprador sea reiteradamente incumpliente.

d) Al mismo tiempo, la reserva de propiedad hace de garantía (impropia) para el vendedor, en una situación en que, no siendo posible recurrir a la publicidad de la venta y tampoco a la hipoteca mobiliaria, el vendedor estaría expuesto a los peligros de la enajenación, por parte del comprador, a terceros de buena fe. La reserva de la propiedad ocupa el lugar, prácticamente, del pacto comisorio (que está prohibido), aunque difiera de él jurídicamente.

Rivera" plantea que la función especial de la reserva de dominio y que la configura como figura autónoma, debe ser la posibilidad de recuperar el bien vendido a plazos. Ello se producirá a través de los mecanismos resolutorios, considerando que la reserva de dominio introduce una condición resolutoria expresa en el contrato al que va incorporada.

\section{Accesoriedad del pacto de reserva}

Conviene aclarar, en primer lugar, para evitar confusiones, que en el Derecho Romano clásico la palabra contractus no significó el acuerdo

9 Manuel Rivera, La posición del comprador en la venta a plazos con pacto de reserva de dominio, Tirant lo Blanch, Valencia, 1994, p. 47. 
de voluntades, que es el sentido moderno que tiene, sino la relación jurídica o el vínculo obligatorio en sí (la obligación). El acuerdo de voluntades (consentimiento) adquirió significado en el Derecho justinianeo y fue llamado pactum o conventio y no contractus.

Inicialmente el solo acuerdo de voluntades (nuda pacta) no producía acción alguna. Para que esto último ocurriera se requería que el pacto se envolviera en algún tipo de ropaje (pacta vestita) que le diera valor obligatorio.

Surgen así los pactos verbales (verbis) cuya vestimenta era el uso de palabras o ritos solemnes (como la stipulatio); los pactos literales (literis) que se formalizan escribiéndolos en un documento del deudor o en un libro del acreedor; y los pactos reales (re) que sólo se perfeccionaban con la entrega de la cosa.

Posteriormente se empieza a admitir el pacto consensual (consensus) que concedía acción por el mero acuerdo de voluntades, sin necesidad de ropaje especial, pero para ello era necesario que ese pacto recayera en convenciones de uso frecuente e importancia práctica. Cada uno de estos pactos así sancionados por el Derecho civil formaba un contrato y estaba designado por un nombre especial: compraventa, arrendamiento, sociedad y mandato. Petit ${ }^{10}$ dice que en Derecho romano los contratos son, pues: unas convenciones o pactos que están destinados a producir obligaciones y que han sido sancionados y nombrados por el Derecho civil.

De acuerdo con el Diccionario de Derecho usual ${ }^{11}$, en el Derecho positivo vigente subsiste el concepto de pacto, pero ya únicamente como cómodo sinónimo del legislador, que alterna la palabra con la de contrato y quizás más aún con la de cláusula de un contrato. Ratificando esta actitud, el Código Civil español declara en su artículo $1.255^{\circ}$ que "los contratantes (lo que supone la celebración de un contrato) pueden establecer los pactos, cláusulas y condiciones que tengan por conveniente", de donde resulta indiscutible que se valoran aquéllos cual parte de los contratos.

Ataz y otros ${ }^{12}$ dicen que la palabra pacto se utiliza en distintos lu-

10 Eugéne Petit, Tratado elemental de Derecho romano, Editorial Nacional, México, 1976, p. 318.

11 Diccionario Enciclopédico de Derecho usual, de Guillermo Cabanellas, voz "Pacto", Editorial Heliasta S.R.L., Buenos Aires, 1988, Tomo VI, p.6.

12 Joaquín Ataz López, Isabel González Pacanowska, Enrique Quiñonero Cervantes, 
gares del Código Civil español y en ellos no siempre con el mismo significado. A veces se utiliza en el sentido de acuerdo sobre algún punto en particular, mediante el cual las partes introducen alguna modificación en el régimen normal de la institución que sea, con lo cual resulta sinónima de estipulación. En otras ocasiones el pacto no afecta el contenido propio del tipo contractual, sino que resulta un añadido que alude a particulares reglas o disposiciones contractuales.

Obsérvese que existe una difundida tendencia a reconocer que el concepto de pacto ha evolucionado, dejando éste de ser considerado exclusivamente como un equivalente del contrato para convertirse en un convenio accesorio de un contrato determinado, que no puede modificar su tipo.

Diez-Picazo ${ }^{13}$ admite la existencia de tal tendencia al decir que en las leyes modernas laten dos sentidos distintos de la palabra pacto, una que se identifica con contrato, y otra que alude a las particulares reglas o disposiciones contractuales. Así por ejemplo cuando se habla del pacto comisorio, del pacto de retroventa, del pacto anticrético en la prenda, de pacto expreso en la redención del censo, se habla siempre de una singular disposición contractual. El mismo autor ${ }^{14}$ anota que las reservas de dominio han sido estudiadas por la doctrina y contempladas por la jurisprudencia como pactos contractuales y, por consiguiente, como ingredientes de una relación jurídico-obligatoria.

El artículo $1583^{\circ}$ del Código Civil peruano está ubicado en el subcapítulo II que tiene el título "Compraventa con reserva de propiedad", que, a su vez, forma parte del Capítulo I que versa sobre "Pactos que pueden integrar la compraventa", donde también está situado el sub-capírulo III que se refiere al "Pacto de retroventa". Resulta así que en el tema de la reserva de propiedad el significado de pacto es en el segundo sentido de que habla Diez-Picazo, o sea el de particular regla contractual.

Dando al pacto este último sentido, surge el problema de su accesoriedad respecto del contrato de compraventa.

Antonio Reverte Navarro, Juan Roca Guillamon y Erncarna Serna Meroño en Comentarios al Código civil y compilaciones forales, dirigidos por Manuel Albaladejo, Editorial Revista de Derecho privado, Madrid, 1993, Tomo XVII, Vol. 1-A, p. 145.

13 Luis Diez-Picazo, Fundamentos de Derecho civil patrimonial, Editorial Tecnos, Madrid, 1979, Vol. I, p. 230.

14 Ibidem, Vol. II. p. 665. 
Un grupo de autores, entre los que cabe citar a Bianca ${ }^{15}$ y a Bocchini ${ }^{16}$, quienes otorgan a la reserva de dominio una función de garantía del vendedor, opina que, si bien el pacto como accesorio de la compraventa presupone la existencia del contrato principal, no existe inconveniente para que la garantía surja no sólo en el momento de celebrarse la compraventa, sino también durante la ejecución de la misma hasta el momento del pago total del precio.

Otro sector de la doctrina considera que la reserva de propiedad debe ser estipulada contextualmente a la compraventa, aunque por distintas razones Greco y Cottino ${ }^{17}$ entienden que la falta de contextualidad determina que la reserva sea ineficaz e inoponible a terceros. Pérez y Alguer ${ }^{18}$ discurren que si no se pacta la reserva de propiedad al momento de celebrarse la compraventa, la entrega de la cosa (unida al contrato de compraventa) producirá su efecto propio de transmitir el dominio, por lo cual el posterior pacto de reserva sólo podrá tener el significado de una nueva transmisión a favor del primitivo vendedor.

Considero, basándome en la opinión de Carpino ${ }^{19}$, que la reserva de dominio debe ser contextual a la celebración del contrato de compraventa, desde que no se trata de añadir a una compraventa una cláusula que modifique su estructura y efectos, ya que la operación nace unitariamente. No se está en presencia de dos actos jurídicos distintos, sino de un solo acto caracterizado por los elementos anteriormente indicados.

Si el pacto de reserva es accesorio a la compraventa, con lo cual la más autorizada doctrina está de acuerdo, es verdaderamente difícil entender que un pacto accesorio modifique sustancialmente la finalidad del contrato del cual forma parte, como parece ocurrir en el pacto de reserva de propiedad integrado a la compraventa. Conviene, por ello, detenernos a estudiar la naturaleza del contrato de compraventa.

15 Massimo Bianca C., op. cit., p. 532.

16 Fernando Bocchini, La vendita di cose mobili, Dott. A. Giuffré Editore, Milano, 1994 , p. 324.

17 Paolo Greco y Gastone Cottino, Della vendita, Nicola Zanichelli Editore, Bologna, 1981, p. 436.

18 Blas Pérez González y José Alguer en las anotaciones a la obra Derecho de obligaciones de Ludwig Ennecerus, Bosch, Casa Editorial, Barcelona, 1966, Volumen II, Primera Parte, p. 185 .

19 Brunetto Carpino, en Trattato di Diritto Privato dirigido por Pietro Rescigno, U.T.E.T., Torino, 1984, Tomo XI, p.318. 


\section{El contrato de compraventa}

Como es sabido, tratándose de la compraventa de bienes muebles el Código Civil peruano acoge la teoría del título y el modo, según la cual dicho contrato es el título de adquisición, o sea el acto que por sí solo no transmite el dominio, pero que mediatamente sirve para ello, al justificar el modo, dándole su razón de ser; el modo de adquirir es la entrega del bien, esto es el acto que sirve inmediatamente para la transferencia de la propiedad, tal como lo prescribe el artículo $947^{\circ} \mathrm{del}$ código civil.

En el caso de los bienes inmuebles determinados surge el problema suscitado por el artículo $949^{\circ}$ del mismo código, según el cual la sola obligación de enajenar un inmueble determinado hace al acreedor propietario de él, salvo disposición legal diferente o pacto en contrario. La doctrina nacional está dividida, pues algunos piensan que el contrato de compraventa de bien inmueble no sólo crea la obligación de transferirlo sino también es el medio suficiente de adquisición de la propiedad. Otros opinan que tratándose tanto de la transferencia de bienes muebles como de inmuebles, rige únicamente la teoría del título y el modo.

En otro cuaderno he desarrollado tal problema, exponiendo las razones que me llevan a adoptar esta última posición.

Hay que observar, sin embargo, que en cualquiera de las dos tesis la finalidad característica del contrato puro de compraventa es transferir la propiedad del bien materia de ella.

\section{Dificultad del tema}

Se ha visto que según el artículo $1583^{\circ}$ del código civil, en una compraventa, cuyo precio no haya sido íntegramente pagado puede pactarse que, pese a haberse celebrado el contrato y entregado el bien al comprador -lo que en la compraventa pura de bienes muebles determina la transferencia de la propiedad-, el comprador se reserve la propiedad del bien, con lo cual parece haberse perdido la finalidad del contrato.

¿Puede un pacto integrado en la compraventa variar de manera tan drástica la finalidad de este contrato? Diez-Picazo ${ }^{20}$ se hace una pre-

20 Luis Diez-Picazo, op. cit., Vol. II, p. 665. 
gunta similar diciendo: "No obstante haberse producido la entrega de la cosa y una entrega que objetivamente considerada reviste todos los caracteres de una traditio y no obstante ser la entrega o traditio consecuencia natural de un contrato del que es consecuencia natural la transmisión, las partes quieren que la transmisión no se produzca de momento y que quede diferida para el futuro. ¿Es esto posible? ¿Cómo puede explicarse jurídicamente algo que en principio constituye una distorsión del sistema?".

Una primera reacción ante este cuestionamiento fue negar la validez del pacto de reserva. Al respecto el jurista italiano Bonelli ${ }^{21}$ sostuvo que el pactum reservati dominii no puede ser un mero pacto agregado a la compraventa, sino una sustancial transformación de dicho contrato, que cuando más podrá ser una promesa de venta, pero de ningún modo un contrato de venta.

Sin embargo, posteriormente el mismo jurista, y con él la mayoría de la doctrina, aunque con construcciones diversas, ha afirmado la plena validez del pacto de reserva de dominio.

Para justificar esta posición se han ensayado diversas soluciones que se plasman en sendas teorías.

\section{1) Teoría de la condición suspensiva}

Es la teoría tradicional, seguida también por autores modernos, la cual afirma, en sustancia, que se trata de una compraventa sujeta a la condición suspensiva del pago íntegro del precio.

En nuestro sistema jurídico, la condición ha sido definida por León Barandiarán ${ }^{22}$ como un hecho futuro e incierto que subordina los efectos del acto jurídico. En el caso de la condición suspensiva se debe esperar su verificación para que el acto produzca sus efectos.

Puede observarse que, según este criterio, la condición suspensiva afecta al acto jurídico en su integridad, suspendiendo todos sus efectos. El acto existe, pero carece totalmente de eficacia.

Aplicando tal concepción al contrato de compraventa, resulta que, pese a haberse celebrado el contrato, la condición suspensiva determina

21 Cita de Francisco Degni, La compraventa, Edirorial Revista de Derecho Privado, Madrid, 1957, p. 225.

22 José León Barandiarán, Comentarios al Código Civil peruano, Ediar S. A. Editores, Buenos Aires, 1954, p. 221. 
que no exista obligación del vendedor de transferir la propiedad del bien mueble -mediante su entrega- ni obligación del comprador de pagar su precio en dinero, que son los efectos fundamentales de la compraventa.

En la compraventa con pacto de reserva de dominio no ocurre esto, pues pese a que en virtud de la condición suspensiva impuesta al contrato de compraventa no habría surgido aún la obligación de entregar el bien, el vendedor debe efectuar esta entrega -aunque conservando el dominio del bien- y el comprador debe pagar el precio -aunque dilatado en el tiempo-.

\section{2) Teoría de la condición resolutoria}

Según esta teoría, el contrato mismo de compraventa estaría sujeto a la condición resolutoria de no pagarse el precio en la oportunidad debida. La propiedad del bien pasaría inmediatamente, tras la celebración del contrato y posterior tradición, al comprador, pero el contrato quedaría resuelto en la eventualidad de que éste dejara de pagar el precio al vencimiento del plazo convenido para el pago.

López de Zavalía ${ }^{23}$ participa de esta teoría, con la aclaración de que más que una condición resolutoria en sentido técnico, debe hablarse de un pacto comisorio. Para comprender esta posición debe tenerse presente que la doctrina argentina moderna denomina "pacto comisorio" tanto a la resolución por incumplimiento cuanto a la cláusula resolutoria expresa, llamándolas pacto comisorio tácito y pacto comisorio expreso, respectivamente. Según López de Zavalía, la reserva de dominio, al igual que el pacto comisorio, opera resolutoriamente.

En apoyo de esta posición está el argumento de Diez-Picazo ${ }^{24}$ según el cual el riesgo pasa del vendedor al comprador con la entrega, de tal manera que si la cosa se pierde en poder el comprador, se pierde para él que será obligado además a pagar el precio. De aquí se deduce que la condición no puede ser nunca suspensiva y será en todo caso resolutoria.

23 Fernando J. López Zavalía, Teoría de los contratos, Víctor P. de Zavalía Editor, Buenos Aires, 1976, Parte especial, Tomo I, p. 260.

24 Luis Diez-Picazo, op. cit., Tomo I, p. 666. 
Se ha objetado esta posición manifestando que la condición resolutoria deja sin efecto un contrato que no solamente existe sino también tiene plena eficacia hasta que la condición se realice. En consecuencia, la celebración del contrato de compraventa y la entrega del bien transfieren al comprador la propiedad de éste, que no queda reservada al vendedor.

\section{3) Teoría de la reciprocidad de prestaciones}

Rubino ${ }^{25}$ sustenta esta teoría diciendo que la figura de la compraventa con reserva de dominio no es anómala, pues se funda en la propia naturaleza especial de la venta como contrato con atribuciones patrimoniales recíprocas: que esta reciprocidad debe existir no sólo en el momento estático de la conclusión del contrato, consistiendo entonces en la necesidad de que sean pactadas y determinadas las dos atribuciones patrimoniales recíprocas (el llamado sinalagma genético), sino que debe subsistir también en el momento dinámico de la ejecución del contrato, consistiendo entonces en la necesidad de que ambas prestaciones sean realizadas (sinalagma funcional). Ahora bien, la mejor aplicación de la reciprocidad en el momento de la ejecución tiene lugar cuando las dos atribuciones tienen lugar contemporáneamente; y así como de un lado las partes pueden fijar a su arbitrio un plazo para el pago del precio, de otro lado, son libres para diferir la transferencia del derecho a un momento sucesivo a la conclusión del contrato, de tal manera que la antedicha contemporaneidad se obtiene precisamente difiriendo la atribución patrimonial correspondiente al vendedor, esto es la transferencia del derecho, al momento en que el precio sea pagada íntegramente.

Este planteamiento ha sido seguido, casi literalmente, por el Tribunal Supremo de España en su sentencia de 10 de junio de 1958.

\section{4) Teoría del derecho real de garantía}

El tratadista alemán Blomeyer ${ }^{26}$ sostiene una tesis de equiparación entre

25 Domenico Rubino, La compravendita, Dott. A. Giuffré Editore, Milano, 1971, p. 429.

26 Cita de Ramón Badenes Gasset, El contrato de compraventa, Librería Ramón Bosch, Barcelona, 1979, Tomo I, p. 509. 
la reserva de dominio y el derecho de prenda, válida para el ordenamiento alemán. Según esta tesis, el acreedor prendario tiene sobre el bien prendado el mismo derecho que sobre el precio: una participación sobre la propiedad, por lo cual la prenda queda sometida a una copropiedad cuyas cuotas no se pueden determinar hasta el momento de su liquidación, pues depende del precio que se obtenga. Agrega este autor que en la reserva de dominio se da una transmisión condicional con fines de garantía y será la marcha del negocio de compraventa la que determine a quién se debe atribuir la plena propiedad y a quién el derecho real de garantía durante el período de pendencia.

Bercovitz ${ }^{27}$ piensa que esta tesis es aplicable al ordenamiento español, equiparando la reserva de dominio a la prenda sin desplazamiento o hipoteca mobiliaria, en cuanto el bien sería de propiedad del comprador y el vendedor tendría sobre ella un derecho real de índole pignoraticia que garantizaría su crédito.

Sobre la base de estas elaboraciones se ha desarrollado ${ }^{28}$ un planteamiento según el cual debe distinguirse entre la reserva de propiedad y la reserva de dominio, ya que debe reconocerse que la reserva de dominio es un derecho peculiar, que tiene un típico contenido de garantía. Queriendo expresar el fenómeno en términos más ceñidos a su efectiva naturaleza, puede decirse, sin más, que el vendedor conserva un típico derecho real de garantía. En el lenguaje corriente tal derecho encuentra una denominación específica propia como "reserva de dominio".

De otro lado, la posición del comprador se presenta con los riesgos, los deberes, las facultades y los poderes que caracterizan la propiedad: falta solamente la limitación conexa a la garantía que compete al vendedor. Resulta congruente admitir que el comprador es ya propietario, porque el concurrente derecho del vendedor representa una limitación en función de garantía, que es comparible con la titularidad y el ejercicio del derecho de propiedad.

\section{5) Venta de otro derecho}

El artículo $1470^{\circ}$ del Código Civil italiano dispone que la venta es el contrato que tiene por objeto la transferencia de la propiedad de una

27 Cita de Mariano Alonso Pérez, op. cit., p. 366.

28 Massimo Bianca C., op. cit., p. 530. 
cosa "o la transferencia de otro derecho" contra la compensación de un precio.

El jurista italiano Bocchini ${ }^{29}$ plantea que el pacto de reserva de dominio es conciliable con la transferencia de un derecho distinto a la propiedad contra el respectivo pago de una suma de dinero.

Esta posición tiene un interés histórico para nosotros pues el artículo $1556^{\circ}$ del Proyecto de Código Civil aprobado por la Comisión Reformadora establecía que por la compraventa el vendedor se obliga a transferir al comprador la propiedad de un bien, "u otro derecho", y el comprador se obliga a pagarle un precio cierto en dinero.

Al amparo de este dispositivo se habría podido sostener una tesis similar a la de Bocchini.

Sin embargo, la Comisión Revisora modificó el artículo $1556^{\circ}$ del citado Proyecto, suprimiendo la expresión "u otro derecho", con lo cual la compraventa sólo es apta para la transferencia del derecho de propiedad.

\section{6) Posición personal}

Pienso que la solución del problema relacionado con la naturaleza de la compraventa con reserva de propiedad, que es la denominación dada por el sub-capítulo II del Capítulo que versa sobre los pactos que pueden integrar la compraventa, debe ser encontrada a la luz de las disposiciones de nuestro Código Civil y, en especial, del contrato de compraventa.

En efecto, el propósito de este cuaderno no es elaborar una construcción jurídica que permita solucionar idealmente los problemas teóricos a que da lugar un pacto tan complejo como es el de la reserva de propiedad, prescindiendo del tratamiento que le ha dado nuestro ordenamiento legal, sino encontrar una explicación razonable a la fórmula utilizada por este ordenamiento.

Sobre la base de las ideas matrices que Lohmann ${ }^{30}$ extrae del texto del artículo $1583^{\circ}$ del código civil puede hacerse el siguiente análisis de dicho texto.

29 Fernando Bocchini, op. cit., p. 293.

30 Juan Guillermo Lohmann Luca de Tena, Temas de Derecho civil, Universidad de Lima, Lima, 1991, p. 238. 
a) La reserva de propiedad es un pacto que puede integrar el contrato de compraventa.

b) En virtud de dicho pacto, el vendedor se reserva la propiedad del bien materia del contrato.

c) El bien es entregado al comprador, quien responde de su pérdida o deterioro desde el momento de la entrega.

e) La reserva dura hasta que se haya pagado todo el precio o una parte determinada de él.

f) El comprador adquiere automáticamente el derecho a la propiedad del bien con el pago del importe del precio convenido.

Conviene analizar a través de que teoría pueden lograrse todas las características antes relacionadas.

a) De acuerdo con el artículo $1529^{\circ}$ del código civil, por el contrato típico de compraventa el vendedor se obliga a transferir la propiedad de un bien al comprador y éste a pagar su precio en dinero. La obligación de transferir la propiedad al comprador se cumple mediante la entrega del bien, tratándose de muebles, y la concurrencia del artículo $949^{\circ}$ del mismo código, en el caso de inmuebles. La obligación de pagar el precio se cumple ejecutando íntegramente el pago.

Se ha visto que la reserva de propiedad no es un contrato sui generis, distinto de otros contratos típicos o atípicos, sino un pacto accesorio al contrato de compraventa que le confiere determinado efecto, sin alterar su naturaleza. La reserva de dominio, dada su accesoriedad al contrato de compraventa, solo opera en el ámbito de este contrato.

La condición, por su parte, es también un elemento accesorio del acto jurídico que no modifica su naturaleza, sino que se limita a suspender o resolver su eficacia. No existe inconveniente conceptual, pues, para que la reserva de propiedad juegue el rol de una condición impuesta al contrato de compraventa.

b) El rol fundamental del contrato típico de compraventa, su verdadera razón de ser, es la transferencia de la propiedad del bien del vendedor al comprador. Así lo dice el artículo $1529^{\circ}$ del código civil.

El pacto de reserva de propiedad frustraría esta finalidad de la compraventa si el efecto del pacto fuera absoluto, esto es si impidiera definitivamente la transferencia de la propiedad al comprador, desde que la compraventa dejaría de ser un contrato traslativo de dominio, con lo cual dejaría, en verdad, de ser una compraventa. 
Sin embargo, el artículo $1583^{\circ}$ del código civil pone claramente de relieve que la reserva de propiedad no tiene vocación de permanencia pues debe terminar bien sea cuando el comprador pague el precio o una parte convencionalmente determinada de él, o bien, aunque no lo diga, cuando deje de ser reserva por resolverse el contrato de compraventa.

Sabemos que el pago del precio no es un acto potestativo del comprador, sino que está obligado a ello por ser la ejecución de una prestación mediante la que se cumple una de las dos principales obligaciones que surgen de la celebración del contrato de compraventa: la de pagar el precio en dinero. Si el comprador no cumple oportunamente esta obligación, puede el vendedor pedir alternativamente la realización del pago o la resolución del contrato por incumplimiento.

Sin embargo, no existe inconveniente jurídico para que el pago del precio, sin perder su obligatoriedad, sea diferido en el tiempo, bien sea postergando su ejecución en el futuro o bien fraccionándola en varios plazos sucesivos.

Por otro lado, si bien la obligación de transferir la propiedad se produce normalmente con la celebración de la compraventa, tampoco existe inconveniente para postergar esta obligación a una oportunidad futura.

En estas condiciones, el pacto de reserva de propiedad, tal cual está regulado por el artículo $1583^{\circ}$ del código civil, no desnaturaliza el contrato de compraventa sino le imprime únicamente un rasgo especial, limitando uno de sus efectos.

Cabe preguntarse ‘hace bien el artículo $1583^{\circ}$ del código civil al hablar de "reserva de la propiedad"?

Lohmann ${ }^{31}$, después de analizar el artículo $923^{\circ}$ del código civil que define la propiedad, considera que el vendedor con reserva de propiedad carece de los poderes inherentes a ella, como son usar, disfrutar y disponer y sólo ostenta un reducido derecho opositorio que a duras penas puede calificarse de reivindicatorio. Por ello, plantea que se use la denominación de "reserva de dominio", que sugiere el peculiar señorío jurídico que mantiene el vendedor para sí, pero sin que ello implique la plena conservación de todos los atributos inherentes a la propiedad.

31 Ibidem, p. 241. 
Sin embargo, parece que no puede hacerse una separación tajante entre "propiedad" y "dominio".

Arias-Schreiber ${ }^{32}$ cita la opinión de Ricardo Ruiz Serramalera según la cual "dominio y propiedad han sido utilizados unas veces como sinónimos y otras con significación diferente, en el sentido que la primera es el género y la segunda es la especie. Si alguna diferencia pudiera establecerse es que entre una y otra expresión no estaría representada por la extensión de su respectivo contenido, sino que solo estaría matizada por la perspectiva desde la que se contempla el poder y señorío que representa el derecho. Visto desde el ángulo objetivo de la ley, la propiedad constituye una relación jurídica caracterizada por su valor patrimonial o económico, visto desde el ángulo subjetivo de la persona, el dominio representa la potestad que sobre la cosa tiene el titular. Elegir uno cualquiera de estos dos términos es, en todas las ocasiones, más una cuestión de preferencia que una decisión lógica, si se tiene en cuenta que, en general, interesa más aquella relación objetiva que este aspecto subjetivo. Cuando se estudia teóricamente el contenido y el comportamiento de un derecho determinado, parece que es aconsejable utilizar con preferencia la palabra propiedad".

De acuerdo con el Diccionario de Derecho usual ${ }^{33}$ sin escrúpulos pueden emplearse como sinónimos "propiedad" y "dominio", y así se advierte en las leyes que también alternan los términos de sus titulares (propietario y dueño). Empero, reconoce que algunos autores como Gregorio López y otros antiguos consideraban más extenso el "dominio" que la "propiedad". Contrariamente, los autores modernos (Azcaráte, Viso, Marfa) sostienen que a la voz "propiedad" debe dársele un sentido genérico, que incluya todas las relaciones jurídicas de esa naturaleza, lo mismo la totalidad de ellas que cada una en particular; mientras que el "dominio" tiene un sentido específico que denota el conjunto de esas relaciones cuando está indiviso.

Por su parte, Castan ${ }^{34}$ opina que, entre dominio y propiedad, no hay diferencias de extensión y contenido y que debe eliminarse una

32 Max Arias-Schreiber Pezet, op. cit., Tomo IV, p. 165.

33 Guillermo Cabanellas, op. cit., voz "Propiedad", Tomo VI, p. 463.

34 Mateo Goldstein en Enciclopedia Jurídica Omeba, voz "Dominio", Driskill S.A., Buenos Aires, 1993, Tomo IX, p. 326. 
disputa bizantina alrededor de un asunto que carece de verdadero contenido jurídico y legal.

Comprendo la preocupación de Lohmann porque, efectivamente, el derecho que se reserva el vendedor no reúne todos los requisitos que el artículo $923^{\circ}$ del código civil atribuye a la propiedad pero, por otro lado, ante la incertidumbre respecto a las diferencias entre "propiedad" y "dominio", pienso que no vale la pena sustituir una expresión por la otra pues con ello no se gana en precisión.

Quizá la mejor redacción del artículo $1583^{\circ}$ del código civil hubiera sido que puede pactarse que el comprador no adquiere la propiedad del bien hasta que se haya pagado el precio, con lo cual se permitiría inferir que no adquiere todos los atributos de la propiedad, algunos de los cuales se reservaría el vendedor.

La finalidad de la reserva de que trata el citado artículo $1583^{\circ}$ es permitir al vendedor, mediante la respectiva acción resolutoria, recuperar absoluta e inmediatamente el bien en caso de incumplimiento del comprador en el pago puntual del precio.

Lo único que falta resolver es la razón por la cual se pacta la reserva de propiedad.

La teoría del derecho real de garantía pretende justificar la reserva de propiedad argumentando que ésta cumple el rol de una garantía real, semejante a la prenda sin desplazamiento posesorio, constituida sobre el bien para asegurar el pago total del precio. En realidad, nuestro ordenamiento no permite una construcción de tal naturaleza, dado el numerus clausus de los derechos reales. Por otro lado, tal como dice Alonso $^{35}$, garantía real y reserva de dominio son instituciones incompatibles, incluso contradictorias, pues si el vendedor se reserva la propiedad del bien, aunque muy debilitada, ya no podemos decir que se la traspasamos al comprador y sobre la misma constituimos un derecho real de garantía sin desplazamiento en beneficio del vendedor.

Tampoco la teoría de la reciprocidad de las prestaciones resuelve el problema. Esta teoría no explica cómo, si la deuda del precio se va reduciendo por razón de las amortizaciones que haga el comprador, la prestación recíproca, constituida por la reserva de propiedad, se mantenga incólume hasta el pago total del precio.

35 Mariano Alonso Pérez, op. cit, p. 368. 
En cambio, según se verá más adelante, no existe inconveniente para que la transferencia de la propiedad esté condicionada suspensivamente al pago del precio.

c) La tercera peculiaridad del contrato de compraventa con reserva de propiedad según nuestro código civil es que, no obstante que el vendedor se reserva la propiedad del bien, éste es entregado al comprador para su uso y disfrute.

El artículo $1583^{\circ}$ del código civil dice que la reserva de propiedad opera aunque el bien haya sido entregado al comprador, lo que podría entenderse en el sentido que la entrega no es un requisito para que se configure al compraventa con reserva de propiedad.

Sin embargo, tal interpretación sería equivocada. Como bien dice León Barandiarán ${ }^{36}$ comentando el artículo $1427^{\circ}$ del código civil de 1936, la utilización del giro "aunque la cosa hubiera sido entregada al comprador" no debe inducir a equivocación: siempre como condición inherente al pacto, debe ser entregada la cosa al comprador. Sostiene Rivera $^{37}$, con toda razón, que la entrega del bien vendido al comprador constituyen una vez perfeccionado el contrato de venta con reserva de dominio, un requisito esencial de la misma. La función económicojurídica de la venta a crédito así lo exige.

El efecto peculiar de esta entrega es que -no obstante que según la teoría del título y el modo cuando se ha celebrado el contrato de compraventa, que es el título de adquisición, la entrega del bien mueble al comprador es el modo de adquirir su propiedad- en la compraventa con reserva de propiedad el vendedor efectúa la entrega del bien, conservando la propiedad del mismo.

Surge la primera duda respecto al rol que juega la entrega si es que ella deja de ser el modo de adquirir la propiedad -desde que el vendedor la conserva-. Una explicación plausible es la dada por Rezzonico ${ }^{38}$ quien dice que mientras no se cumpla la condición suspensiva -0 sea el pago total del precio- y aunque la cosa se entregue al comprador bajo esa condición, éste solo tiene la "tenencia y facultad de usarla", pero no la posesión plena -entendida como el ejercicio de un poder

36 José León Barandiarán, op. cit., Tomo I, p. 77.

37 Manuel Rivera, op. cit., p. 82.

38 Luis María Rezzonico, op. cit., Tomo I, p. 405. 
inherente a la propiedad (artículo $896^{\circ}$ del código civil) - pues reconoce el dominio del vendedor: tiene el ius possessi (posesión de hecho, sin ser propietario, pero con justo título), pero no el ius possidendi (derecho de poseer, como facultad inherente al derecho de propiedad).

Esta explicación está orientada a esclarecer el hecho de que mediante la condición suspensiva de transferir el dominio, que no significa el condicionamiento de la compraventa en sí, se frustre el efecto de la compraventa según la teoría del título y el modo que es, precisamente, que la entrega sea el modo de adquirir la propiedad. Resulta, pues, que la entrega no se efectúa para hacer propietario al comprador, sino para permitirle el uso del bien, como ocurre, por ejemplo, en el contrato de arrendamiento.

Los autores tratan de explicar el título en virtud del cual la entrega el bien concede la posesión del mismo al comprador, e invocan para ello la situación de comodatario, arrendatario, administrador, precarista, depositario, o alguna otra análoga. Pienso que no es necesario recurrir a otras fuentes para justificar la naturaleza jurídica de la situación posesoria del comprador, pues para ello basta la existencia del contrato de compraventa con reserva de propiedad. Es en virtud de la celebración de este contrato y de la consiguiente entrega obligatoria del bien al comprador que se constituye la posesión del mismo por el comprador.

Sin embargo, este resultado sólo puede lograrse a través de una condición que se limite a suspender el efecto propio de la entrega que genera la perfecta ejecución de la teoría del título y el modo aplicada al contrato de compraventa: la transmisión de la propiedad. De esta manera, la compraventa con pacto de reserva de dominio produciría todos los efectos de la compraventa respecto tanto a las obligaciones del vendedor -inclusive la entrega- cuanto a las obligaciones del comprador, con excepción de la obligación de transferir al comprador la propiedad del bien, que queda suspendida hasta que este pague la totalidad del precio.

La primera dura que surge es saber si se puede condicionar solo la producción de uno de los efectos del acto jurídico, dejando incondicionados los demás. En otras palabras, si es posible que la condición no recaiga en el acto jurídico como tal sino en uno de los elementos de la relación jurídica creada por él. 
Según Vidal ${ }^{39}$ la condición es un hecho futuro e incierto que arbitrariamente y por la sola voluntad de los declarantes se incorpora al acto jurídico, el que le queda supeditado en cuanto a la producción de sus efectos. Parecería, pues, que la condición afecta la totalidad de los efectos del acto jurídico.

Sin embargo, dado que la condición depende del arbitrio del declarante no existe inconveniente conceptual alguno para que ella no subordine todos los efectos del acto jurídico sino solamente determinados de ellos. No es que todo el acto jurídico pierda eficacia, desde que es posible que esta ineficacia sea parcial, o sea limitada a un determinado efecto.

Al respecto, Albaladejo ${ }^{40}$ admite que la condición puede alcanzar una cláusula singular del contrato, de manera que se quiera en parte puramente y en parte bajo condición. Galgano ${ }^{41}$, por su lado, afirma que la autonomía contractual permite someter a condición suspensiva alguna cláusula y no otras y, en particular, la obligación de una parte y no la obligación de la otra, eventualidad en la cual aquella obligación existirá pero no producirá efecto alguno hasta la ocurrencia de la condición. Entre nosotros, Lohmann ${ }^{42}$ reconoce que es función propia de la condición suspender o resolver todos o algunos de los efectos del negocio.

De acuerdo con esta doctrina cabe admitir, pues, que solo la obligación de transferir la propiedad del bien mediante su entrega quede sometida a la condición suspensiva de pagarse íntegramente el precio. Tal como dice López de Zavalía ${ }^{43}$, con esta concepción el bien debe ser entregado, pero la entrega que se verifica no es traslativa de propiedad, ya que la transmisión del dominio queda subordinada a la condición suspensiva de que se pague el precio. Según esta tesis, el contrato de compraventa es incondicionado, y lo único condicionado es la transmisión del dominio.

39 Fernando Vidal Ramírez, op. cit., p. 236.

40 Manuel Albadadejo, Derecho civil, Librería Bosch, Barcelona, 1975, Tomo 1, Volumen II, p. 188 .

41 Francesco Galgano, El negocio jurídico, Tirant lo Blanch, Valencia, 1992, p. 156.

42 Juan Guillermo Lohman Luca de Tena, El negocio jurídico, Editora Jurídica Grigley, E.I.R.L., Lima, 1994, p. 294.

43 Fernando J. López de Zavalía, op. cit., Tomo I, p. 258. 
Aun admitiendo esto surge una segunda duda, esta vez relacionada con la posibilidad de que el pago del precio, que es uno de los elementos esenciales del contrato de compraventa, sea considerado como una condición de la transferencia de la propiedad.

Los elementos del acto jurídico se clasifican en esenciales, naturales y accidentales. Son elementos esenciales aquellos elementos sin los cuales el acto jurídico no podría existir, o no podría tener validez; por ejemplo, la declaración de voluntad, el objeto. Se consideran elementos naturales aquellos elementos que son consecuencia de la celebración de cada acto jurídico, o sea los que no siendo esenciales del acto, se entienden pertenecerle sin necesidad de cláusula especial; por ejemplo, el saneamiento por evicción y vicios ocultos, la gratuidad en el depósito. Son accidentales los elementos que, no obstante no existir naturalmente en el acto jurídico, son susceptibles de ser agregados para modificar los efectos normales del acto jurídico; por ejemplo, la condición, el plazo.

Tratándose del contrato de compraventa, sus elementos esenciales especialísimos son la estipulación del bien materia de la transferencia de propiedad y del precio pagadero en dinero. En estas condiciones, sostiene Bocchini ${ }^{44}$, no es posible que el precio, y por tanto su pago, que representa un elemento esencial del contrato de compraventa, pueda representar contemporáneamente el objeto de un elemento accidental de dicho contrato.

Sin embargo, lo que es elemento esencial del contrato de compraventa es la existencia del precio, que puede ser determinado o determinable, pero no su pago, que sólo constituye la ejecución de la prestación en que consiste la obligación respectiva. Una vez establecidas las obligaciones de transferir la propiedad del bien y de pagar su precio en dinero, el contrato de compraventa queda celebrado incondicionalmente, aun cuando el efecto traslativo de propiedad que normalmente corresponde a la entrega en la compraventa quede condicionado al pago total del precio. Debe tenerse presente que el pago del precio, si bien no es meramente potestativo del comprador desde que está obligado a hacerlo por razón de la celebración de la compraventa, puede ser futuro e incierto.

44 Fernando Bocchini, op. cit., p. 297. 
Podría objetarse que de acuerdo con el artículo $172^{\circ}$ del código civil, es nulo el acto jurídico cuyos efectos están subordinados a condición suspensiva que dependa de la exclusiva voluntad del deudor.

En el caso de la reserva de propiedad la condición suspensiva no sólo no es, como se acaba de ver, meramente potestativa sino tampoco depende de la voluntad del deudor.

En efecto, debe tenerse presente que en este caso el acreedor de la obligación condicionada es el comprador, desde que mediante el pago del precio adeudado, que es la condición suspensiva, él va a adquirir automáticamente el derecho a la propiedad del bien. Como bien dice Messineo $^{45}$, no es nula la asunción de la obligación si depende de la voluntad (aun mera) del acreedor (esto es de aquel a cuyo favor se asume el deber de cumplimiento).

Cabe, por lo tanto, admitir que la teoría de la condición suspensiva ofrece una respuesta adecuada al problema a la entrega del bien sin transmitir su propiedad.

El artículo $1583^{\circ}$ del código civil prescribe, como se ha visto, que el comprador asume los riesgos de pérdida del bien o deterioro desde el momento de su entrega.

Tratándose del contrato de compraventa típico, el artículo $1567^{\circ}$ del código civil dispone que el riesgo de pérdida de bienes ciertos, no imputable a los contratantes, pasa al comprador en el momento de la entrega.

Puede observarse que ambas reglas son iguales, no obstante que en la compraventa típica la entrega, al menos en el caso de los bienes muebles, es el modo de transferir la propiedad, mientas que en la compraventa con reserva de dominio la entrega, como se ha visto, no transmite la propiedad, que queda reservada al vendedor.

Se han dado diversas razones para justificar la solución dada por el artículo $1583^{\circ}$ del Código Civil peruano, cuyo antecedente inmediato es el artículo $1523^{\circ}$ del Código Civil italiano.

En primer lugar, observa Oertman ${ }^{46}$ existe un "clarísimo motivo de política jurídica: el comprador, a pesar de la reserva, tiene ya la posesión y las utilidades de la cosa, puede con más facilidad que nadie

45 Francesco Messineo, Doctrina general del contrato, Ediciones Juridicas EuropaAmérica, Buenos Aires, 1948, Tomo I, p. 198.

46 Cita de Manuel Rivera, op. cit., p. 74 
prevenirla contra los peligros, y así lo hará, si se establece la transmisión del riesgo, por un fundado egoísmo, con mucho más cuidado y energía que si ningún perjuicio pudiera prevenirle de la inutilidad de la defensa de la cosa".

Por otro lado, destaca Alonso ${ }^{47}$, que "si el comprador, por la tradición posesoria, usa, goza y hasta abusa de la cosa sin que haya abonado el precio en su totalidad, parece normal que soporte el periculum".

Finalmente, Garrigués ${ }^{48}$ sostiene que "el paso del riesgo no se opera por la transmisión de la propiedad, sino simplemente por el hecho de la puesta a disposición del comprador".

Estas razones justifican la solución dada por el artículo $1583^{\circ} \mathrm{del}$ código civil. Cabe destacar que tal justificación no obedece a que la naturaleza de la compraventa con reserva de propiedad requiera necesariamente que el comprador asuma el riesgo de la pérdida o deterioro del bien, pues con similar razón pudo haberse dado la solución opuesta, o sea que el vendedor, como propietario del bien, soporte el riesgo de su pérdida, sino constituye una solución de equidad.

d) La cuarta característica de la compraventa con reserva de propiedad es que dicha reserva dura hasta que se haya pagado todo el precio o una parte determinada de él. Si bien es frecuente que se estipule que el traslado de la propiedad al comprador solo se efectúe cuando el precio haya sido íntegramente pagado, no existe inconveniente alguno para pactar que es suficiente pagar una proporción determinada del precio para que se deje sin efecto la reserva de propiedad. En tal sentido, la condición suspensiva estaría limitada al pago de la parte del precio que las partes hayan fijado.

e) La quinta y última particularidad de la compraventa con reserva de propiedad es que, tal como lo establece el segundo párrafo del artículo $1583^{\circ}$ del código civil, el comprador adquiere automáticamente el derecho a la propiedad del bien con el pago del importe del precio convenido.

Sostiene Lohmann ${ }^{49}$ que no debe decirse que se adquiere el "derecho a la propiedad" ya que, a su entender, lo que de verdad se adquiere

47 Mariano Alonso Pérez, op. cit., p. 373.

48 Joaquín Garrigues, Curso de Derecho Mercantil, Imprenta Aguirre, Madrid, 1969, Tomo II, p. 83.

49) Juan Guillermo Lohmann Luca de Tena, op. cit, p. 246. 
al acabar de pagar es el definitivo derecho de propiedad, que el vendedor deberá perfeccionar.

De acuerdo con el artículo $1529^{\circ}$ del código civil, por la compraventa el vendedor se obliga a transferir la propiedad de un bien. Lo que se adquiere por la compraventa es, pues, el "derecho a la propiedad" del bien. El definitivo derecho de propiedad se transfiere mediante el modo de adquirir, que está constituido por la entrega, en el caso de bienes muebles, y por la concurrencia del artículo $949^{\circ}$ del código civil, en el caso de bienes inmuebles. Tratándose de la compraventa con reserva de propiedad, el levantamiento de la reserva por razón del pago del precio da lugar a que el comprador adquiera el "derecho a la propiedad".

Es cierto, sin embargo, que en esta clase de compraventa es requisito indispensable la entrega al comprador del bien materia de la compraventa en el momento de celebración del contrato, por lo cual al acabar el comprador de pagar el precio ya se habrá producido la entrega y, por consiguiente, la obligación de transferir se habrá ya cumplido.

Según Bigio ${ }^{50}$, quien adquiere el bien de acuerdo con el segundo párrafo del artículo $1583^{\circ}$ del código civil, lo hace en forma automática. No se requiere declaración judicial, ni de declaración adicional del vendedor ni de sus herederos. Una vez que el comprador paga el precio o la cuota necesaria para la adquisición de la propiedad, es titular del bien con prescindencia de cualquiera de dichas declaraciones.

Esto guarda concordancia con la calidad de condición suspensiva que tiene el pago del precio, desde que una vez cumplida la condición el acto jurídico condicionado se convierte automáticamente en puro y simple (se "purifica"). Tal como dice Albaladejo ${ }^{51}$, cumplida la condición suspensiva se producen ipso iure los efectos del negocio (acto jurídico).

Por la misma razón, debe entenderse que, a diferencia de lo que ocurre en otros ordenamientos extranjeros, en el sistema peruano la adquisición del bien por el comprador se produce a partir del momento del pago de la última armada del precio, ya que de conformidad con

50 Jack Bigio Chrem, "Exposición de Motivos Oficial del Código civil" Separata Especial del diario oficial El Peruano, de 24 de marzo de 1990, p. 8.

51 Manuel Albaladejo, El negocio jurídico, Librería Bosch, Barcelona, 1958, p. 264. 
el artículo $177^{\circ}$ del código civil, la condición no opera retroactivamente, salvo pacto en contrario.

Por lo demás, tal como se dice en la Exposición de Motivos del artículo $1583^{\circ}$ del código civil ${ }^{52}$, se ha optado por la solución de que la adquisición de la propiedad por el comprador se produce con efecto retroactivo al momento del pago de la última armada del precio, debido a razones prácticas, tales como los inconvenientes que traería otorgarle retroactividad al momento de la entrega para efectos tributarios, adquisición de frutos por el vendedor, gravámenes constituidos por el vendedor, etc.

Debe tenerse presente que para que funcione el pacto de reserva de propiedad no se requiere necesariamente que el saldo de precio por pagar esté dividido en armadas o cuotas periódicas, bastando que dicho saldo sea diferido en el tiempo, aunque fuere en única solución.

$\mathrm{El}$ análisis que precede permite llegar a la conclusión que la teoría que mejor responde a la naturaleza de la compraventa con reserva de propiedad, tal como está legislada por el código civil, es la de la condición suspensiva, que es apta para cumplir las cinco características de este contrato.

Por otro lado, la función de la reserva de propiedad resulta estar limitada a garantizar al vendedor el cobro del precio mediante la retención del derecho de propiedad. Ninguna otra ventaja ofrece en comparación con una compraventa pura cuyo precio sea dilatado en el tiempo, pues en ambos casos deberá recurrirse a los mecanismos resolutorios.

\section{Resolución del contrato}

El hecho de la reserva de propiedad del bien por el vendedor no significa que éste, ante el incumplimiento del comprador en el pago de lo que falta del precio, tenga el derecho de recuperar ipso jure la posesión del bien, privando al comprador de su derecho al uso del mismo mediante una acción reivindicatoria. Para lograr este resultado se requiere que, previamente, se deje sin efecto el contrato de compraventa.

52 Código civil: Exposición de Motivos y Comentario, Compiladora: Delia Revoredo de Debakey, Okura Editores S.A., Lima, 1985, Tomo VI, p. 235. 
La compraventa con reserva de propiedad, por ser una modalidad de la compraventa, es un contrato con prestaciones recíprocas.

En tal virtud, es de aplicación el artículo $1428^{\circ}$ del código civil, según el cual en los contratos con prestaciones recíprocas, cuando alguna de las partes falta al cumplimiento de su prestación, la otra parte puede solicitar el cumplimiento o la resolución del contrato y, en uno u otro caso, la indemnización de daños y perjuicios. A partir de la fecha de citación con la demanda de resolución, la parte demandada queda impedida de cumplir su prestación.

La resolución, cuyo resultado es dejar sin efecto el contrato, debe ser materia de pronunciamiento judicial salvo los casos de los artículos $1429^{\circ}$ y $1430^{\circ}$ del código civil.

En el primer caso, producido el incumplimiento del comprador en el pago del precio, el vendedor puede requerirlo mediante carta por vía notarial para que efectúe el pago, dentro de un plazo no menor de quince días, bajo apercibimiento de que, en caso contrario, el contrato quede resuelto. Si el pago no se efectúa dentro del plazo señalado, el contrato queda resuelto de pleno derecho, quedando a cargo del comprador la indemnización de daños y perjuicios.

En el segundo caso, puede convenirse expresamente que el contrato se resuelva cuando el comprador no cumpla con el pago puntual del precio. La resolución se produce de pleno derecho cuando el vendedor comunica al comprador que quiere valerse de la cláusula resolutoria.

Para que el vendedor pueda recurrir al mecanismo resolutorio, si el pago del precio debe efectuarse por armadas en diversos plazos, se requiere, de conformidad con el artículo $1561^{\circ}$ del código civil, que el comprador deje de pagar tres de ellas, sucesivas o no, caso en el cual el vendedor puede pedir la resolución del contrato o exigir al vendedor el inmediato pago del saldo, dándose por vencidas las cuotas que estuvieren pendientes.

Sin embargo, el mecanismo resolutorio tropieza con el grave obstáculo colocado por el artículo $1562^{\circ}$ del mismo código, según el cual en el caso del artículo $1561^{\circ}$, el vendedor pierde el derecho a optar por la resolución del contrato si se ha pagado más del cincuenta por ciento del precio, siendo nulo todo pacto en contrario.

Realmente, la institución de la compraventa con reserva de propiedad parece perder todo interés con esta restricción por cuanto la resolución del respectivo contrato es la clave de todo el sistema. En efecto, 
se ha visto que en caso de incumplimiento del comprador en el pago puntual del precio la única manera como el vendedor puede recuperar la posesión del bien es mediante la resolución de la compraventa. La aplicación de la regla contenida en el artículo $1562^{\circ}$ del código civil determina que una vez pagada la mitad del precio, el comprador no podrá pedir la resolución del contrato, quedando limitado su derecho al cobro del precio adeudado.

Bigio $^{53}$ destaca que la Comisión Revisora del Código Civil fue consciente que la regla general del artículo $1562^{\circ}$ de dicho código resta eficacia al pacto de reserva de propiedad si el comprador carece de bienes al momento del incumplimiento.

Relata el mismo jurista que durante los debates para la aprobación de este precepto y del texto del artículo $1562^{\circ}$ del código civil se consideró la posibilidad de que la reserva de propiedad fuera una excepción a la regla general contenida en el artículo $1562^{\circ}$. En otras palabras, se discutió arduamente acerca de que la reserva de propiedad pueda permitir al vendedor la resolución por falta de pago, aunque el comprador haya pagado más del $50 \%$ del precio. Finalmente primó la tesis de dos miembros de la Comisión en el sentido que, de consagrarse la excepción, los contratantes burlarían la prohibición del artículo $1562^{\circ}$ y harían de la compraventa con reserva de propiedad una práctica usual. De convertirse la compraventa con reserva de propiedad en moneda corriente, la generalidad de contratos estarían expuestos a la resolución por falta de pago.

"El legislador ha expresado que muchas son las razones que han pesado para impedir que la compraventa con reserva de propiedad sea resuelta cuando el comprador ha pagado más del $50 \%$ del precio. La principal ha sido la de preservar el principio general contenido en el artículo $1562^{\circ}$ del código civil, inspirado en el propósito de favorecer el acceso a la propiedad a sectores mayoritarios de la población. Además debe tenerse en cuenta que la única situación en la que el vendedor se encuentra menos protegido es aquella en la que el comprador ha pagado más del $50 \%$ del precio y no tiene bienes que respalden el cumplimiento

53 Jack Bigio Chrem, op.cit, p. 9. 
de su obligación. A ello debe agregarse que el vendedor ha podido solicitar garantías reales o una fianza; o también ha podido pactar una reserva de propiedad sujeta a la condición resolutoria del pago del $51 \%$ del precio y una hipoteca bajo condición suspensiva en virtud de la cual sólo regiría dicha garantía cuando el comprador pague el referido porcentaje".

Hay que advertir que la posición de la Comisión Reformadora del Código Civil peruano no es singular. Considera Langle ${ }^{54}$ que la aplicación general del mecanismo resolutorio a la compraventa a plazos con reserva de dominio en que el adquirente ya ha pagado la mayor parte o casi todo el precio produce verdaderas iniquidades. Cita, al respecto, los esfuerzos legislativos que se han hecho en Alemania, Austria e Italia para poner remedio a esta situación, consistentes principalmente en establecer límites mínimos a la suma de los pagos en retardo, superados los cuales la resolución no funciona.

Lohmann ${ }^{55}$ se pregunta si el artículo $1562^{\circ}$ del código civil es de preceptiva observancia en todas la modalidades de compraventa, o si, por el contrario, no rige para la reserva, inclinándose a pensar que dicho numeral también juega contra la reserva, pues nada figura en contrario. Comparto la opinión de este autor nacional, ya que la resolución por incumplimiento en el caso de la compraventa con reserva de propiedad no es distinta de la resolución en otros casos de contratos de compraventa.

Desde luego, por constituir el artículo $1562^{\circ}$ del código civil una excepción a la regla general del arrículo $1428^{\circ} \mathrm{del}$ mismo código sólo funciona en el caso del artículo $1561^{\circ}$, o sea cuando el precio debe pagarse por armadas en diversos plazos, no siendo de aplicación por analogía a casos diversos, de acuerdo con lo que dispone el artículo IV del Tírulo Preliminar del Código en referencia. Por ejemplo, no funcionaría el artículo $1562^{\circ}$ si se hubiera pagado al contado el $50 \%$ o más del precio y se hubiera diferido el pago del saldo total a una fecha futura, desde que no existen armadas pagaderas en distintos plazos.

54 Emilio Langle y Rubio, El contrato de compraventa mercantil, Bosch Casa Editorial, Barcelona, 1958 , p. 184.

55 Juan Guillermo Lohmann Luca de Tena, op. cit., p. 256. 
En principio no estoy de acuerdo con las normas legales que protegen el incumplimiento de las obligaciones imputable al deudor. Creo que debe fomentarse, en todo lo posible, el principio contenido en el artículo $1361^{\circ}$ del código civil, según el cual los contratos son obligatorios en cuanto se haya expresado en ellos, y que sólo cabe dejar de lado esta regla en los casos de lesión o de excesiva onerosidad de la prestación.

\section{Compensación por el uso del bien}

El artículo $1426^{\circ}$ del Código Civil de 1936, referente a la venta con reserva de propiedad, establecía que si el precio debiera ser pagado en cuotas sucesivas, los contratantes estipularían la parte del precio recibida que el vendedor puede hacer suya como indemnización de perjuicio en caso de rescindirse la venta por no haberse pagado totalmente el precio.

El Código Civil de 1984 no ha recogido esta norma considerando, posiblemente, que su artículo $1563^{\circ}$ contempla una situación similar, aplicable a todas las modalidades de compraventa. Este artículo tiene la siguiente redacción:

Artículo $1563^{\circ}$.- La resolución del contrato por incumplimiento del comprador da lugar a que el vendedor devuelva lo recibido, teniendo derecho a una compensación equitativa por el uso del bien y a la indemnización de los daños y perjuicio, salvo pacto en contrario.

Alternativamente, puede convenirse que el vendedor haga suyas, a título de indemnización, algunas de las armadas que haya recibido, aplicándose en este caso las disposiciones pertinentes sobre las obligaciones con cláusula penal.

De acuerdo con la Exposición de Motivos de este artículo ${ }^{56}$, resulta justo que el vendedor deba devolver al comprador la parte del precio que haya recibido, pues éste es el efecto normal de toda resolución por

56 Código Civil, Exposición de Motivos y Comentarios, op. cit., p. 223. 
incumplimiento. Sin embargo, como el comprador ha tenido el uso del bien desde el momento en que se le entregó, también resulta justo que pague al vendedor una compensación equitativa por dicho uso, además de la indemnización de los perjuicios que le haya causado con su incumplimiento.

Comentando el artículo $1526^{\circ}$ del Código Civil italiano, que constituye uno de los antecedentes del artículo $1563^{\circ}$ del Código Civil peruano, dice Bocchini ${ }^{57}$ que, contrariamente a lo que se piensa, esta norma está orientada a refrenar o contener la práctica contractual impuesta a los vendedores, por lo cual, en la hipótesis de resolución del contrato por incumplimiento del comprador, el vendedor tiene derecho a la restitución de la cosa y a retener las cuotas cobradas, a título de compensación por el uso de la cosa por parte del comprador.

Esta retención está limitada, de un lado, al importe necesario para repagar por el uso del bien realizado por el comprador y por el normal deterioro del mismo y, de otro lado, al eventual resarcimiento de los daños causados por el comprador al bien. De allí que el juez, según las circunstancias, puede reducir con criterio equitativo el monto de las cuotas pagadas retenidas por el vendedor a título de compensación.

Dice el artículo $1563^{\circ}$ del código civil que, alternativamente, puede convenirse que el vendedor haga suyas, a título de indemnización, algunas de las armadas que haya recibido. Observándose que, a diferencia de la compensación equitativa por el uso del bien y de la indemnización de los daños y perjuicios, que funciona por mandato de la ley, en el caso de la retención a título de indemnización se requiere de un convenio entre el comprador y el vendedor para que éste haga suyas algunas de las armadas de precio que haya recibido.

\section{Oposición del pacto a los acreedores}

El primer párrafo del artículo $1584^{\circ}$ del código civil establece que la reserva de propiedad es oponible a los acreedores del comprador sólo si consta por escrito que tenga fecha cierta anterior al embargo.

En virtud de la reserva de propiedad el vendedor conserva un dere-

57 Fernando Bocchini, op. cit., p. 337. 
cho real sobre el bien que puede oponer erga omnes, incluyendo los acreedores del comprador.

El artículo $1584^{\circ}$ exige que la reserva conste por escrito, pero se refiere exclusivamente al documento probatorio para que la reserva sea oponible a terceros. La escritura no tiene relación con la validez ni eficacia de la reserva entre las partes, por lo cual puede estar contenida en una declaración bilateral sucesiva a la conclusión del contrato, siempre que la intención contractual se haya expresado unitariamente. En otras palabras, el contrato de compraventa con reserva de dominio, esto es incluyendo el pacto de reserva (recuérdese que debe ser contextual al contrato), puede ser celebrado verbalmente o de otra manera que no sea la escritura, pero se requiere que el pacto de reserva figure por escrito, para efectos probatorios.

Con la misma finalidad probatoria se exige que el documento escrito sea de fecha cierta anterior al embargo. El artículo $2704^{\circ}$ del Código Civil italiano preceptúa que la fecha del documento privado cuya firma no ha sido autenticada no es cierta y computable respecto a terceros, sino desde el día en que el documento ha sido registrado o desde el día de la muerte o de la sobrevenida imposibilidad física de aquel que lo ha firmado o de uno de aquellos que lo han firmado, o desde el día en que el contenido del documento se reproduce en actos públicos o, finalmente, desde el día en que se verifica otro hecho que establezca de un modo igualmente cierto la anterioridad de la formación del documento.

No se requiere que la fecha cierta sea la de estipulación del contrato con pacto de reserva, sino simplemente, como lo dice el primer párrafo del artículo $1584^{\circ}$ del código civil, que sea anterior el embargo.

De acuerdo con el segundo párrafo del mismo artículo, si se trata de bienes inscritos, la reserva de la propiedad es oponible a terceros siempre que el pacto haya sido previamente registrado.

$\mathrm{Al}$ respecto debe tenerse presente que el artículo $2019^{\circ}$ del código civil dispone que son inscribibles en el registro de la propiedad inmueble los pactos de reserva de propiedad y de retroventa, agregando el artículo $2045^{\circ}$ del mismo código que estos pactos son inscribibles en los registros de bienes muebles.

Según Bianca ${ }^{58}$, la especial publicidad de la reserva de propiedad

58 Massimo Bianca C., op. cit., p. 5541. 
alcanzada a través de la inscripción en el respectivo registro excluye la posibilidad que el vendedor pueda ser perjudicado para la adquisición de un tercero. La buena fe del adquirente es irrelevante porque la inscripción está expresamente dirigida a resolver a favor del vendedor inscribiente el conflicto con los terceros, y esta solución tiene significado aún respecto a los adquirentes de buena fe.

Respecto a los adquirentes de mala fe se discute si la falta de registro determina que la reserva sea inoponible a estos adquirentes. La mejor doctrina opina que el vendedor con reserva de propiedad no podría oponer su título al tercero adquirente de mala fe por cuanto el sistema delineado en el segundo párrafo del artículo $1584^{\circ}$ implica desapego al principio que disciplina la adquisición a non domino de los bienes muebles.

\section{Prueba del derecho de reserva de propiedad frente a terceros}

El vendedor que ejercira el derecho de reserva de propiedad debe probar el hecho constitutivo, esto es la estipulación del pacto.

En cambio, el vendedor no tiene a su cargo la prueba de la falta de pago del precio.

\section{Transferencia por el comprador}

Se discute en doctrina si el comprador puede transferir el bien a un tercero.

Si bien se justifica que el comprador no pueda transferir a un tercero la propiedad del bien, desde que no la tiene, en cambio no es objetable que el comprador transfiera sus derechos sobre el bien, que son, sustancialmente, el de uso del bien y el de adquirir la propiedad del mismo cuando se termine de pagar el precio.

Para este último efecto será necesario realizar la correspondiente cesión de derechos. 


\section{El arrendamiento-venta}

El artículo $1585^{\circ}$ del código civil dispone que las disposiciones de los artículos $1583^{\circ}$ y $1584^{\circ}$ son aplicables a los contratos de arrendamiento en los que se convenga que, al final de los mismos, la propiedad del bien sea adquirida por el arrendatario por efecto del pago de la merced conductiva pactada.

La doctrina francesa conoce desde antiguo la figura del arrendamiento-venta, según la cual los vendedores a plazos han convertido esa operación en un arrendamiento acompañado de una venta a término; el comprador figura como arrendatario que adquirirá el bien cuando haya pagado cierto precio, debiendo deducirse. Señalan Planiol y Ripert $^{59}$ que los vendedores, ante el temor de que se pudiera sostener que la operación encubierta tras el arrendamiento es en realidad una venta traslativa de propiedad, han admitido que el comprador estará obligado a pagar un precio ligeramente superior al total de los alquileres; de esta suerte la venta queda notoriamente distinguida del arrendamiento, a pesar de la unidad del contrato.

Comentando el último párrafo del artículo $1526^{\circ}$ del Código Civil italiano, que constituye el antecedente inmediato del artículo $1585^{\circ}$ del Código Civil peruano, dice Capozzi ${ }^{60}$ que con esta norma el legislador ha resuelto un viejo problema, nacido sobre todo en la doctrina francesa, relativo a la considerada locación con fines de venta, "respecto a la cual se han propuesto varias construcciones (locación acompañada de promesa de venta, venta sujeta a condición, venta sujeta a termino, contrato mixto) ha configurado, pura y simplemente, el instituto como compraventa con reserva de propiedad.

En otras palabras, agrega, si Tizio conviene que pagará por diez años a Cayo, propietario del departamento "A", el canon mensual de un millón de liras por el uso del departamento y las partes establecen, al mismo tiempo, que al décimo año, si Tizio cumple con el pago, devengará, automáticamente en propietario, el contrato, aunque configurado impropiamente como locación, será, en la realidad jurídica y en la consiguiente disciplina, una venta con reserva de propiedad. La

59 Marcel Planiol y Georges Ripert, Tratado práctico de Derecho civil francés, Cultural S.A., Habana, 1946, Tomo X, p. 235.

60 Guido Capozzi, op. cit., p. 130. 
citada norma no ha, de este modo, querido extender la disciplina de la compraventa con reserva de propiedad a un contrato con contenido diverso sino ha querido reconocer que la llamada locación con fines de venta tiene sustancialmente la naturaleza de compraventa y como tal es calificada y regulada.

Cabe destacar, por último, que tal como dice Arias-Schreiber ${ }^{61}$ no debe confundirse esta figura con el arrendamiento financiero o leasing, contemplado por el artículo $1677^{\circ}$ del código civil y por el Decreto Legislativo $\mathrm{N}^{\circ} 299$, pues su naturaleza y alcances son diferentes.

61 Max Arias-Schreiber Pezet, op. cit., Tomo II, p. 121. 